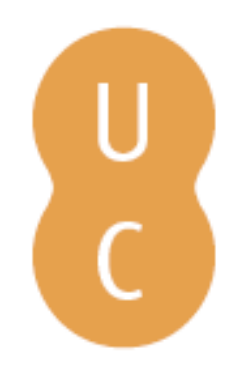

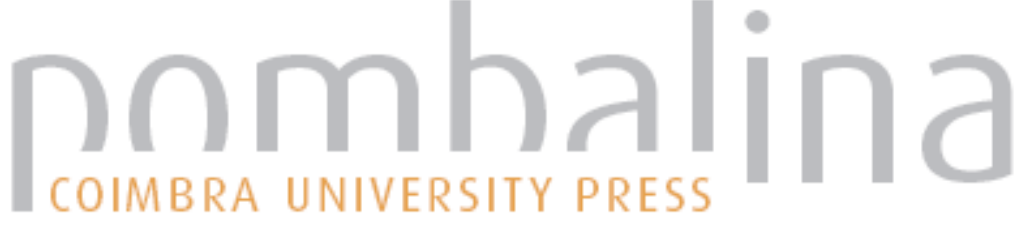

\section{Método e empiria em Hegel}
Autor(es):
Ferrer, Diogo
Publicado por: Imprensa da Universidade de Coimbra
URL persistente:
URI:http://hdl.handle.net/10316.2/32228
DOI:
DOl:http://dx.doi.org/10.14195/978-989-26-0361-2_4

Accessed : $\quad$ 26-Apr-2023 14:40:23

A navegação consulta e descarregamento dos títulos inseridos nas Bibliotecas Digitais UC Digitalis, UC Pombalina e UC Impactum, pressupõem a aceitação plena e sem reservas dos Termos e Condições de Uso destas Bibliotecas Digitais, disponíveis em https://digitalis.uc.pt/pt-pt/termos.

Conforme exposto nos referidos Termos e Condições de Uso, o descarregamento de títulos de acesso restrito requer uma licença válida de autorização devendo o utilizador aceder ao(s) documento(s) a partir de um endereço de IP da instituição detentora da supramencionada licença.

Ao utilizador é apenas permitido o descarregamento para uso pessoal, pelo que o emprego do(s) título(s) descarregado(s) para outro fim, designadamente comercial, carece de autorização do respetivo autor ou editor da obra.

Na medida em que todas as obras da UC Digitalis se encontram protegidas pelo Código do Direito de Autor e Direitos Conexos e demais legislação aplicável, toda a cópia, parcial ou total, deste documento, nos casos em que é legalmente admitida, deverá conter ou fazer-se acompanhar por este aviso.

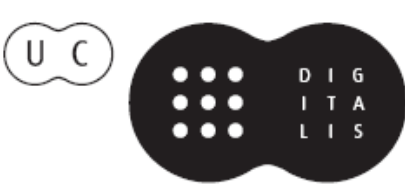


Diogo Ferrer

Coordenação

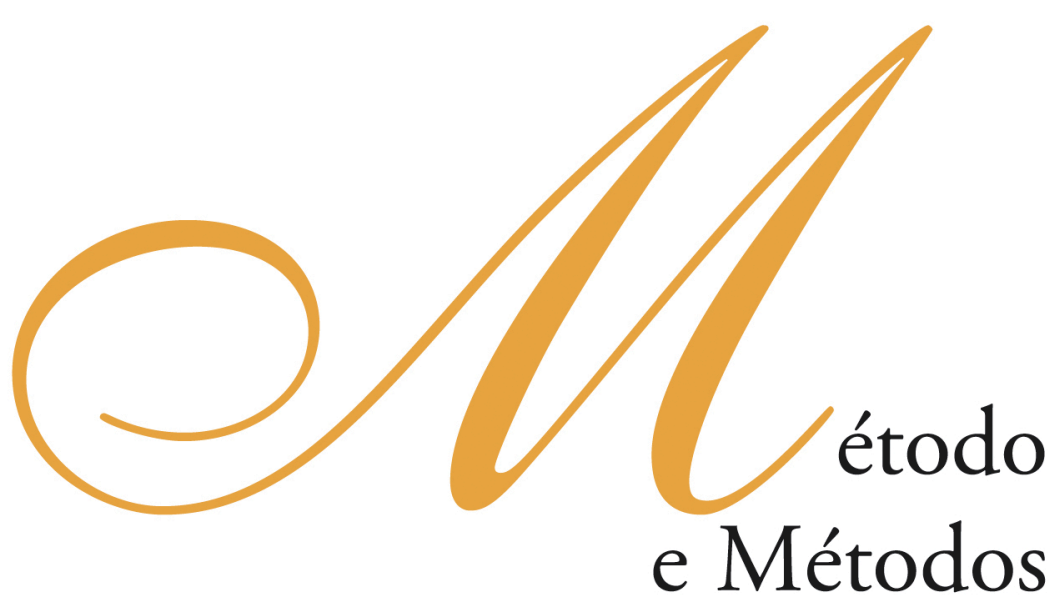

do Pensamento Filosófico 


\section{COORDENAÇÃO EDITORIAL \\ Imprensa da Universidade de Coimbra}

URL: http//www.imp.uc.pt

\section{CONCEPÇÃO GRÁFICA}

António Barros

PRÉ-IMPRESSÃO

Victor Hugo Fernandes

EXECUÇÃO GRÁFICA

Inova - Artes gráficas

ISBN

989-8074-02-7

DEPÓSITO LEGAL

$257236 / 07$

(C) Março 2007, Imprensa da Universidade de Coimbra

OBRA PUBLICADA COM O APOIO DE:

Centro de Estudos Clássicos e Humanísticos

FCT Fundação para a Ciência e a Tecnologia MINISTÉRIO DA CIÊNCIA E DA TECNOLOGIA 
Diogo Ferrer

Coordenação

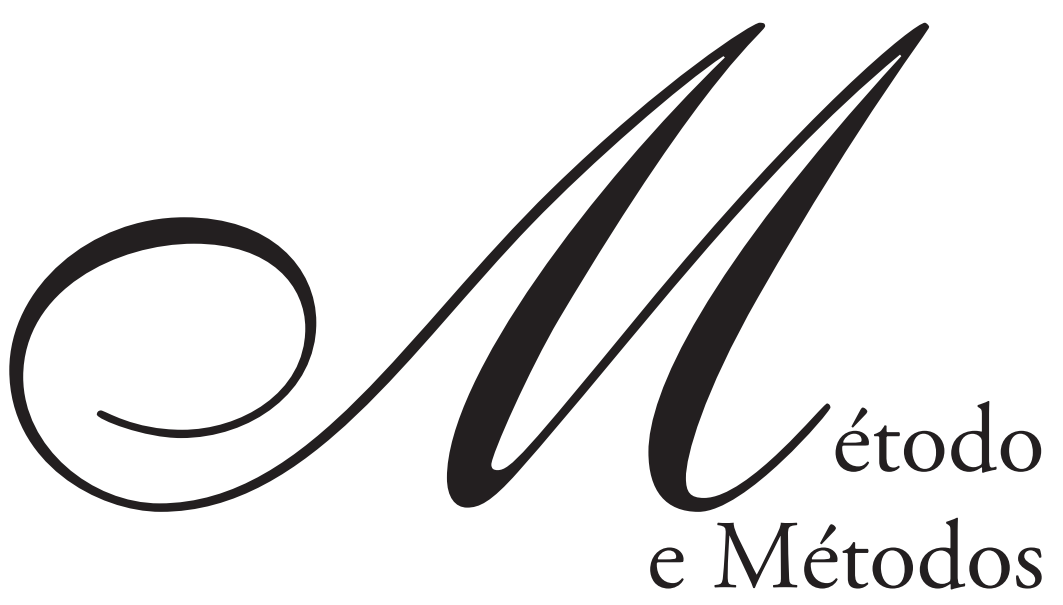

do Pensamento Filosófico

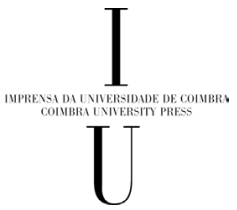

- COIMBRA 2007 



\section{Diogo Ferrer \\ Universidade de Coimbra}

\section{Método e Empiria em Hegel}

Ao encerrar a época moderna e abrir, em muitos aspectos, a contemporaneidade, a filosofia de Hegel retoma uma matriz fundamental do pensamento moderno, expressa no título da obra programática de Descartes, o Discurso do Método. O método, buscado e adoptado então, sobretudo na modernidade, como instrumento de potenciação das possibilidades de conhecimento, teve uma influência histórica decisiva por força de duas das suas características teóricas centrais: a idealização e abstracção matemática, por um lado; e, por outro, a necessidade de uma fundamentação, de tipo subjectivo, do conhecimento, a que a filosofia procura dar resposta. Assim, se Hegel retoma os grandes temas do pensamento moderno, procurando mostrar que conduzem a dualismos insatisfatórios, e resolver esses dualismos, a sua tematização e emprego do método também se orienta de modo a criticar e resolver o carácter abstracto e unilateralmente idealizador do método.

Na primeira característica, a da idealização e abstracção quantitativa, reside tanto o êxito da aplicação do método quanto a sua principal insuficiência no que toca à fundamentação filosófica. A regularidade que o método imprime ao conhecimento conduz à eliminação da complexidade implicada na sobreposição, no objecto, de diferentes níveis de categorização relevando das mais diferentes esferas da realidade. Assim, um mesmo objecto, dotado de aspectos físicos quantitativos, pertence funcionalmente a diferentes organizações macrocósmicas mais complexas, tem aspectos qualitativo- 
-subjectivos, mas também psicológicos, simbólicos, culturais ou outros, de que se faz abstracção sistemática na idealização matemática. O método científico, fundado nesta matemática, procede a uma abstracção dos aspectos que não são tratáveis por experimentação controlada e matematicamente regulada. Uma consequência directa desta regularização e abstracção dos procedimentos é a resolução do método numa técnica do procedimento cognoscitivo. Nos termos de Husserl, «faz parte da essência de todo o método a tendência para se perder numa união com a tecnicização». (1)

Hegel apropria-se da ideia do método, com o programa de romper com esta característica de perda de concretude. A tese hegeliana de que «O próprio método se amplia [...] num sistema» ${ }^{(2)}$, significa que a filosofia vai procurar reconstituir, a partir de uma perspectiva metodologicamente orientada, a concretude objectiva do mundo, sacrificada pela perspectiva idealizadora e abstracta moderna. A ampliação do método em sistema designa a recomposição concreta do existente por uma via que permita satisfazer duas exigências teóricas do pensar. Por um lado, o requisito de compreensão das suas próprias acções. Este requisito de auto-compreensão constitui, na verdade, o que se deveria entender em geral como emprego de um método e elaboração de uma metodologia. É com base nesta constituição necessariamente reflexiva do método, e não com a finalidade de ligar o método filosófico à consciência subjectiva que se pode ler na Introdução à Ciência da Lógica que «o método é a consciência da forma do auto-movimento interno do seu conteúdo»(3). A segunda exigência a que Hegel visa dar resposta é, por outro lado, evitar uma orientação do pensar que, dada a sua parcialidade e fragmentação do existente, promove, subterraneamente,

(1) E. Husserl, Die Krisis der europäischen Wissenschaften und die transzendentale Phänomenologie (Husserliana VI, Haag, 1962), p. 48. Acerca do método em geral, cf. ib. pp. 20-25, 45-48.

(2) "Die Methode selbst erweitert sich [...] zu einem System" (Hegel, Wissenschaft der Logik. Die Lehre vom Begriff, Hamburg, 1994 [= LB], p. 300).

(3) "Die Methode ist das Bewußtsein über die Form der inneren Selbstbewegung ihres Inhaltes» (Hegel, Wissenschaft der Logik. Die Lehre vom Sein, Hamburg, 1990, p. 38). 
uma mais funda desorientação. O método é a reconstituição, no sistema, da ligação entre as diferentes partes e momentos da experiência.

Esta via, em que o pensar se perde na tecnicização que, dada a sua essencial abstracção, ameaça sempre o método, conduz a dualidades no hiato das quais o sujeito se situa, capaz de representar os dois termos, mas não conhecendo o estatuto dessa mesma representação, ou o pensamento que a ela subjaz, dualidades de que corpo e alma, razão e empiria ou significação e facto são exemplos privilegiados.

Apesar da tendência para a perda de concretude, o emprego do método e a explicitação de uma metodologia são indispensáveis para o pensamento filosófico que se possa denominar racional, ou científico. (4) A filosofia é uma ideia que se distingue das produções espirituais ou culturais em geral pelo seu carácter científico e ideal, ou seja, é um projecto de dar razão dos objectos em geral [Gegenstände], onde o «dar razão» tem o significado de explicitação de pressupostos necessários ao discurso justificativo, ou seja, explicitação do próprio logos. A filosofia é, em consequência, um pensar inevitavelmente crítico e reflexivo, e a forma do método dialéctico vai derivar, no fundamental, destas duas características. A crítica opera pelo isolamento da negatividade presente em cada significado ou categoria científica, que permite a sua ligação, por meio de refutação sistemática, a outros significados ou categorias. Este procedimento permite constituir uma sequência lógica de pensamentos dotada de necessidade imanente. A reflexividade, por sua vez, designa tanto a noção de que numa ordem lógica objectiva, cada conteúdo, por assim dizer, reflecte outros conteúdos pertencentes à mesma sequência lógica, quanto a referência que todo o procedimento deve fazer à fonte da discursividade que permite proceder

(4) «Wenn aber die Notwendigkeit ds Begriffs dem losern Gang der räsonnierenden Konversation wie den steifern des wissenschaftlichen Gepränges verbannt, so ist schon oben erinnert worden, da $\beta$ seine Stelle nicht durch die Unmehode es Ahndens und der Begeisterung und die Willkür des prophetischen Redens ersetzt werden soll, welches nicht jene Wissenschaftlichkeit nur, sondern die Wissenschaftlichkeit überhaupt verachtet" (Hegel, Phänomenologie des Geistes, Hamburg, 1988 [=PhG], pp. 36-37). 
numa sequência significativa. Esta fonte de toda a relação inteligível é o sujeito, cuja tematização explícita dentro dessa mesma ordem lógica, e segundo os mesmos princípios da sua constituição, é a figura própria do esclarecimento filosófico e o sentido da racionalidade. Por esta razão, o capítulo final da lógica acerca da denominada ideia absoluta, fonte última de todo significado é, além de uma teoria da subjectividade, principalmente uma metodologia lógica e filosófica.

Para Hegel, o saber [Wissen] explana-se em ciência [Wissenschaft] por meio da apresentação da ligação entre os momentos diversos da articulação em que se gera a significação. Poderá entender-se a sua cientificidade justamente pela ligação, numa unidade concreta, dos diferentes planos em que a ciência moderna cinde, tecnicamente, o seu objecto. A apresentação desta ligação "reconcretizadora» do existente constitui a própria fundamentação ou justificação racional de cada momento articulado, pelo método, no sistema. A filosofia funda os seus conceitos ao inseri-los no sistema, ao considerá-los numa totalidade de sentido. E o método é, então, conforme se viu, correlativo à ideia de sistema, uma diferenciação segundo regras universais, que são, na verdade, tão-só o reconhecimento geral da identidade, ou parentesco, dos significados através do processo de diferenciação. (5) A definição deste parentesco, que é estabelecido à maneira de uma filogénese conceptual, é para ser entendida como reconstrução do fundamento da inteligibilidade do logos, teoria da racionalidade em geral. Nestes termos, aquilo que caracteriza a ideia de justificação racional e de cientificidade é, sem dúvida o método e o sistema. Um tal reconhecimento desta identidade

(5) Poderia caracterizar-se a relação e diferenciação sistemática de elementos como envolvendo uma classificação de tipo filogenético, em que são as relações que definem, ou mesmo que geram o lugar de cada elemento. Esta é uma consequência da ideia de construção sistemática que se impõe mesmo que se funde o pensar num método calculatório. Assim, "unlike other conceptual systems, a constructional system undertakes more than the division of concepts into various kinds and the investigations of the differences and mutual relations between these kinds. In addition, it attempts a step-by-step derivation or "construction" of all concepts from certain fundamental concepts, so that a genealogy of concepts results in which each one has is definite place" (Rudolf Carnap, The Logical Structure of the World, transl. R. George, Chicago, 2003, p. 5). 
significativa é, em última instância, tornado impossível quando o método é tomado como técnica idealizadora e operatória. A distinção entre o método, entendido como uma forma abstracta do pensar, a realizar tecnicamente, e a dialéctica é abordado explicitamente por Hegel em textos introdutórios das suas principais obras, como se verá.(6)

O método é segundo Hegel, pelo contrário, a justificação em permanente explicitação, que permite a génese das significações em séries articuladas, identificáveis, e.g., como disciplinas filosóficas. O estatuto destas séries não é então, em primeiro lugar, o de um conhecimento de proposições e raciocínios, mas o de ordens disciplinares objectivas diversas.

Em consequência, a característica do método de ser, antes de mais, a atenção teórica crítica ao significado daquilo que articuladamente se faz ou enuncia, não se poderia apreender nos termos em que, - num exemplo já distante de Hegel, mas ainda no mesmo âmbito de disputa pelo sentido do método e, mesmo, da modernidade, - Heidegger se refere à lógica: "pelo conhecimento das configurações lógicas fundamentais, dos conceitos e regras do pensar, o nosso pensar se torna consciente do seu próprio proceder; o proceder consciente, por sua vez, oferece a garantia de uma mais elevada segurança e de uma maior acribia. Todo o domínio da técnica do pensar traz proveitos e supremacia.»(7) Com o método, contudo, como Hegel pretende, na sua lógica, pôr em prática, não se trata nem de adquirir certeza ou segurança para o sujeito, nem de dominar uma técnica. Nada estaria mais longe da concepção hegeliana do método do que uma aquisição técnica de certeza para a consciência, porque, na verdade, e já também - agora noutro exemplo igualmente distante de Hegel, mas na origem da

(6) V. PhG, pp. 32-33, 35-36; Wissenschaft der Logik. Die Lehre vom Sein (Hamburg, 1990) [=LS], pp. 39-42; Enzyklopädie der philosophischen Wissenschaften (Frankfurt a.M., 1970) [=EphW] $\S \S 23,78,79$; Grundlinien der Philosophie des Rechts (Hamburg, 1995) [=GphR] §§ 31-32.

(7) "Durch die Kenntnis der logischen Grundgebilde, der Begriffe und Denkregeln, wird unser Denken sich seines eigenen Vefahrens bewußt, das bewußte Vefahren aber bietet die Gewähr einer höheren Sicherheit und einer größeren Schärfe. Jede Beherschung der Denktechnik schafft Vorteile und Uberlegenheit." (Heidegger, Logik als die Frage nach dem Wesen der Sprache, Gesamtausgabe 38, Fankfurt a.M., 1998, p. 7.) 
disputa referida, - mesmo nas Regras para a Direcção do Espírito (8) de Descartes, a reflexão metodológica filosófica não pode deixar de envolver uma actualização permanente da atenção teórica, precisamente o oposto de uma técnica a dominar, que envolve antes, como se referiu, a tendência para o esquecimento do próprio procedimento, em proveito da repetição de actos que se sabem tanto mais eficazes quanto melhor desatendido ou esquecido for o seu processo genético. Enquanto que na citação de Heidegger, a frase inicial liga o método à consciência do procedimento, a segunda liga-o à tecnicização, onde essa consciência tende essencialmente, nos termos de Husserl, a "perder-se». Ela não pode, então, caracterizar daquilo que está em questão com o método hegeliano.

A acepção do método subscrita na concepção de segurança, certeza e supremacia apresentada no excerto de Heidegger, não pode ser confundida com a tese hegeliana de que a justificação é integralmente explicitável no método, ou de que este é essa mesma explicitação integral dos processos. A acepção que determina o método como garantia técnica de supremacia da consciência não pode dispensar a relação de aplicação do método a um material estranho, ou de regras a casos, concepção que Hegel explicitamente recusa para a sua filosofia. Assim, segundo Hegel, "O progresso usual em outras ciências, porém, inteiramente imperfeito, costuma ser que a concreção do universal é somente uma aplicação do universal a um material vindo de alguma outra parte».(9) O método filosófico não consiste, de modo nenhum, numa aplicação.

A sua função é essencialmente reflexiva: o método é um momento de mediação pelo universal, de justificação e, por conseguinte, reflexivo. Pertence por isso a um momento subjectivo do conhecer. Ele pertence, então, ao momento teórico em que o conhecimento é pertença inevitável de um sujeito

(8) Cf. Descartes, Regulae ad directionem ingenii (Adam \& Tannery, Paris, 1996, vol. X), pp. 407-409.

(9) «Der ganz unvollkommene, gewöhnliche Fortgang aber in anderen Wissenschaften pflegt zu sein, daß [...] die Konkretion desselben [sc. des Allgemeinen] nur eine Anwendung des Allgemeinen auf anderswoher hereinkommenden Stoff ist» (LB, p. 269). Cf. também GPhR, § 31. 
ou, noutros termos, em que qualquer unidade de significado, qualquer que seja a dimensão que lhe seja atribuída, só existe para um sujeito que, hoje, diríamos «dotado de intencionalidade» ou de "estados mentais». Se a função significativa só existe para um sujeito, todo o conhecimento discursivo ou conceptual, que lida com significações, tem de estar de algum modo referido a uma subjectividade. A necessidade teorética de explicitar esta referência, com a exigência correlativa de coerência, acompanha sempre o método, com o que se faz, justamente, a lógica acompanhar, nela mesma, de uma teoria da subjectividade. Assim, viu-se que o método começa por ser apresentado, na Introdução à Ciência da Lógica, como «a consciência da forma do auto-movimento interno do conteúdo» da ciência. (10) O método é a consciência no seu estádio epistemológico. A referência à consciência, no entanto, convém apenas a uma apresentação introdutória, uma vez que o método não pode ser entendido como referência ou presença de um sujeito ou consciência exterior. Como saber filosófico, o método, "esta mediação do conceito consigo mesmo, é não só um curso do conbecer subjectivo, mas precisamente, do mesmo modo, o movimento próprio da coisa mesma». (11) E, no capítulo conclusivo da Lógica, então, ele não mais é ligado a alguma forma de consciência, mas "é o método próprio de cada coisa mesma», (12) de tal modo que "o método absoluto, pelo contrário, não se comporta como reflexão exterior, mas toma a partir do seu próprio objecto o [que é] determinado, posto que é o seu princípio imanente e a sua alma». (13) O método perde, ao longo da lógica, a sua característica de consciência para se reconhecer princípio imanente do conteúdo.

Ao método abstracto e idealizador da razão científica, matemática ou lógica formal, Hegel chama «formalismo», o qual somente decalca, ou

(10) LS, p. 38.

(11) Texte zur philosophischen Propädeutik (Werke 4, Frankfurt a.M., 1970), p. 161.

(12) "sie ist die eigene Methode jeder Sache selbst" (LB, p. 286).

(13) «Die absolute Methode dagegen verhält sich nicht als äußerliche Reflexion, sondern nimmt das Bestimmte aus ihrem Gegenstand selbst, da sie selbst dessen immanentes Prinzip und Seele ist" (LB, p. 291). 
simula, a necessária objectividade científica, por uma eliminação imediata do sujeito, que é substituído por regras de tipo técnico para o pensar.

O desiderato científico de objectividade é atingido por uma eliminação somente aparente do sujeito. A univesalidade própria deste é substituída, sem mediação devidamente explicitada, pela generalidade da regra técnica. Esta eliminação imediata do sujeito tem um triplo resultado teórico: por um lado, poderia dizer-se, (a) o sujeito, expulso pela porta, reentra pela janela, com a função de selecção e aplicação das regras, jamais temático e, por isso mesmo, tanto mais arbitrário; em segundo lugar, (b) perde-se uma reflexão capaz de fundamentação última dos seus procedimentos; por fim, (c) tudo o que releva justamente do domínio do objecto na sua concretude integral, qualitativa, significativa ou simbólica, ou seja, principalmente boa parte do domínio natural e a totalidade do domínio espiritual, por suporem figuras objectivadas da subjectividade, ficam por tematizar de maneira adequada, conforme começámos por referir. Observa-se, por esta razão, que a tematização quantitativa, aplicativa e mecânica, se é adequada nos níveis mais imediatos e simples da natureza, torna-se progressivamente menos relevante à medida em que se avança para os domínios significativos da vida, do espírito, da história ou da própria razão.

O método matematizado, a que Hegel chama "matemática filosófica», (14) reconhece pois uma exigência central do método científico, dando-lhe, porém, uma resposta somente aparente. É esta exigência, como se disse, a da objectividade, no sentido de autonomia do conteúdo apreendido relativamente ao sujeito epistemológico, ou seja, de anulação da subjectividade no sentido do que se poderia designar, parafraseando Hegel, uma "má subjectividade», que não se confunde com a necessária reflexão justificadora e universalizadora do conteúdo própria do método e de todo o procedimento racional. A matematização, denominada por Hegel também «formalismo», faz antes simular a objectividade do conteúdo; ao pretender banir inteiramente qualquer

(14) «[P]hilosophische[...] Mathematik» (EphW, § 259A). 
subjectividade, perde qualquer noção de fundamentação, em sentido pleno, dos seus procedimentos. E, na ausência de uma fundamentação última, a subjectividade retorna de modo não temático e não justificado.

Este problema manifesta-se em diferentes características do formalismo. O formalismo é um domínio da regra, com o resultado de que (1) as conexões são exteriores, de tal modo que a necessidade da conexão que vigora entre as determinações não se pode ler no seu próprio conteúdo, mas em regras residentes no conhecimento do sujeito, e cuja aplicação é, do mesmo modo, por ele seleccionada pelo arbítrio do sujeito, que só aparentemente permanece exterior ao processo científico. E estas regras não são entendidas como participando da constituição quer do sujeito quer do conteúdo, que a elas devem justamente permanecer indiferentes. (2) Nestes termos, a ligação, embora necessária, no sentido de obedecer a regras, mantém-se contingente no que toca à sua selecção e à sua ligação com o sujeito e o conteúdo a que se aplica. Os pensamentos são ligados em séries somente ocasionais, e o pensar entendido como actividade exclusivamente do sujeito, a quem basta observar regras que lhe são essencialmente alheias. Segundo Hegel, pelo contrário, a subjectividade deverá ser entendida não como orientadora do processo do conhecimento filosófico a partir do seu exterior, mas como categoria a ser desenvolvida objectivamente como conteúdo temático explícito. Assim, e.g., o próprio conhecimento deverá constituir uma categoria lógica de significado objectivo. (3) Hegel atribui ao cálculo a perda da fluência do conceito, (15) com o que refere a resolução do pensamento em unidades discretas entre si recombináveis sem outra transição para além da referida ligação ordenada ao sujeito exterior. A crítica converge, no plano categorial, (4) na refutação da uma distinção permanente e absoluta entre forma e conteúdo e que pretenda abordar a primeira sem, com isso, se envolver definitivamente e de modo determinado com o conteúdo. O método, ao

(15) Cf. LS, p. 31. 
"dispensar [da ciência] o conteúdo pleno", tem então de o procurar "para ela [sc. a ciência] no [seu] exterior.» (16)

Ressalta, por sua vez, no Prefácio à Fenomenologia a crítica ao procedimento matemático, pela condução das suas demonstrações com base numa finalidade exterior, contra a qual propõe Hegel uma ideia de desenvolvimento do próprio conteúdo, ou seja de algum modo de ligação objectiva entre os conteúdos do pensar. (17) Aí, o "conhecimento é exterior ao material», é um «determinar e tratar exteriores», (18) tornado unicamente possível pela abstracção prévia do objecto a que se aplica a grandeza, o espaço ou o uno. (19) A inadequação de qualquer redução da filosofia à matemática, deriva da "pobreza da finalidade [da matemática] e da insuficiência do seu material». (20) Neste sentido, nas considerações mais tardias das Linhas Fundamentais da Filosofia do Direito, o método consiste numa consideração concreta do objecto, de tal modo que «considerar algo racionalmente não quer dizer trazer uma razão a partir de fora para o objecto, e assim o elaborar, mas o objecto é por si mesmo racional [...]». (21) Mas também na Ciência da Lógica a crítica é prosseguida, fazendo-se notar que o cálculo opera com recurso permanente à comparação "sem conceito". (22) Isto significa que não há referência ao processo de constituição dos elementos envolvidos, entendidos de modo inteiramente discreto, a que Hegel alude justamente como o «uno vazio». "Porque o cálculo é um assunto tão exterior e, por isso, mecânico, foi possível, como se sabe, construir máquinas» de calcular.

(16) «Damit aber entbehr[t] sie des gediegenen Inhaltes [...]; und ein solches [...] pflegt für sie außen gesucht zu werden» (ib). Este ponto baseia-se em Ferrer, Lógica e Realidade em Hegel. A Ciência da Lógica e o Problema da Fundamentação do Sistema (Lisboa, 2006), pp. 154-156.

(17) PhG, p. 32.

(18) Ib. 36.

(19) Ib. 33. V. tb. GPhR, § 31 A.

(20) «... d[ie] Armut ihres Zweckes und d[ie] Mangelhaftigkeit ihres Stoffs» (PhG, p. 33).

(21) «Etwas vernünftig betrachten heißt, nicht an den Gegenstand von außen her eine Vernunft hinzubringen und ihn dadurch bearbeiten, sondern der Gegenstand ist für sich selbst vernünftig [...]»(GphR, § 31A).

(22) "[...] das Quantitative der Bestimmungen»; "äußerlichen Unterschied, auf bloßer Vergleichung»; «ein völlig analytisches Verfahren und begriffloses Kalkulieren» (LS, p. 37). 
"Fazer do cálculo o principal meio de formação do espírito» corresponde a submetê-lo «à tortura de ser aperfeiçoado como uma máquina». (23) A lógica dialéctica opera em ciclos repetidos que reproduzem sempre novamente, em termos muito latos, imediatez, mediação e retorno ao imediato. Este modo de recursividade não é, contudo, de modo nenhum calculável, ou "algoritmizável», (24) no sentido em que existisse quaisquer instruções pré-determinadas que pudessem conduzir aos seus resultados. (25) A impossibilidade de um plano anterior de instruções a levar a cabo, ou de fundação exterior dos seus processos é parte integrante de dois aspectos teóricos fundamentais da lógica: (a) ela pretende fornecer a razão primeira e auto-contida ou auto-explicitada do procedimento racional; e (b) pretende ser teoria da própria acção teórica racional do sujeito. Os dois programas ficariam inviabilizados por um tal nível anterior de instruções capaz de recolher, em invariáveis, o significado do próprio prodecimento lógico. (a) A fundamentação do procedimento não pode ser feita a outro nível teorético, uma vez que ou seria este outro nível a desempenhar propriamente a função da Ciência da Lógica, ou a fundamentação regressaria ao infinito. E (b) a acção teórica do sujeito na lógica seria explicável num nível diferente do seu, não cabendo à própria lógica a teorização dessa acção. Como teoria do método em explicitação integral, a lógica terá de se assemelhar antes a procedimentos de tipo formativo, com características de filogenia, (26) na medida em que envolve classificações conceptuais, ou histórico, por ser simultaneamente cumulativo, no mesmo passo em que permite também

(23) «Weil das Rechnen ein so äußerliches, somit mechanisches Geschäft ist haben sich bekanntlich Maschinen verfertigen lassen»; "Das Rechnen zum Hauptbildungsmittel des Geistes zu machen" corresponde a submetê-lo "auf die Folter, sich zur Machine zu vervollkommen" (LS, p. 230). V. Krämer, Symbolische Maschinen. Die Idee der Formalisierung in geschichtlichem Abriß (Darmstadt, 1988), 98-100. V. tb. Lachterman, "Hegel and the Formalization of Logic" (in Graduate Faculty Philosophy Journal, 12 (1987), pp. 153-236 ) p. 160ss.

(24) Wandschneider, Grundzüge einer Theorie der Dialektik. Rekonstruktion und Revision dialektischer Kategorien-Entwicklung in Hegels "Wissenschaft der Logik» (Stuttgart, 1995), p. 184.

(25) V. Ferrer, loc. cit.

(26) A referência ao carácer "orgânico» do procedimento é vincada no § 31 de GPhR. 
um constante retorno ao imediato, como origem de desenvolvimentos não previsíveis a partir das mediações anteriores.

A dialéctica hegeliana não é, por conseguinte, redutível a regras invariáveis, exclui cuidadosamente, como se viu, a noção de "aplicação", nos seus diferentes sentidos, e os seus resultados não são, então, reconstruíveis a partir da aplicação de regras. Neste sentido, os resultados do método hegeliano são análogos a processos de desenvolvimento de tipo histórico, onde cada momento é singular, não podendo, por isso, repetir-se ou combinar-se com outros sem alterar as suas relações e funções e, com isso, o seu significado. O desenvolvimento da dialéctica, embora siga passos de tipo lógico-refutativo, não pode, em consequência ser considerado como previsível, uma vez dado o seu momento inicial. As regras envolvidas na refutação têm a legitimidade de uma fixação, para o entendimento, de princípios de uma inteligibilidade discursiva imprescindível. Mas são para entender não como uma universalidade exterior ao caso ou ao particular regulado, mas antes como padrão inerente ao desenvolvimento interno ou autónomo do conteúdo particular. Uma tal concepção da regra não deve ser entendida como ausência de regras e arbitrariedade, mas como forma consumada da necessidade objectiva. Hegel recusa, então, o carácter técnico e abstracto do método, retendo a sua característica de subjectivação, enquanto tomada de consciência, e de justificação crítica de procedimentos.

Mas aquilo que a leitura de Hegel permite concluir é que as duas características que atribuímos ao método - a idealização matemática e técnica típicas da ciência moderna, por um lado, e a justificação reflexiva de procedimentos, por outro - não são simplesmente opostas e separáveis, mas constituem momentos diferentes do método. Não é, assim, possível recusar uma simplesmente sem recusar igualmente a outra. A recusa de todo o elemento idealizador e técnico para o pensar envolve também a recusa do seu elemento crítico, de justificação reflexiva e possibilidade de fundamentação última. A dialéctica hegeliana tem, por conseguinte, de reter algo do elemento idealizador e, igualmente, técnico, tendo o estudo 
da dialéctica de passar então, em larga medida, pelo estudo das relações e ordenação entre estes dois planos.

Para definir a relação entre os planos da idealização e abstracção matemática, e o da justificação reflexiva dos procedimentos, será então necessário observar o modo como Hegel aborda os procedimentos e resultados da ciência moderna.

O filósofo define uma ligação estreita entre o método científico e o método filosófico, de tal modo que a filosofia da natureza deve ser entendida, em primeiro lugar, como uma metafísica das ciências, ou do método científico. A sua abordagem da empiria e da ciência positiva não é, por conseguinte, de tipo transcendental ou apriorístico, mas procede post-facto. A epistemologia hegeliana busca encontrar o momento conceptual nos procedimentos matemáticos e experimentais da ciência moderna, sem desmentir jamais a sua lógica própria, ou procurar explicações com eles concorrentes; busca tão-só definir os momentos que permitam uma ordenação significativa mais vasta, ou seja, que os permita integrar num sistema em conjunto com os principais conteúdos do conhecimento lógico, natural ou espiritual. A Enciclopédia hegeliana visa reconstituir uma unidade do saber, como que numa interdisciplinaridade sistemática, estendida à generalidade das ciências, dotando-o, ao mesmo tempo, de uma relação com a filosofia. "A relação da ciência especulativa com as outras ciências é, assim, que ela não deixa porventura de lado o conteúdo empírico destas, mas reconhece-o e utiliza-o, e que do mesmo modo reconhece e emprega, como o seu conteúdo próprio, o universal destas ciências, as leis, as espécies, etc.».(27) Mas se a filosofia pensa a partir de conteúdos científicos, também a ciência não dispensa formas conceptuais apreensíveis pela filosofia. Assim, "há nela [na física] muito mais pensamento do que ela sabe e admite, [...] ela é

(27) «Das Verhältnis der spekulativen Wissenschaft zu den anderen Wissenschaften ist [...] nur dieses, daß jene den empirischen Inhalt der letzteren nicht etwa auf der Seite läßt, sondern ihn anerkennt und gebrauch, [...] und zu ihrem eigenen Inhalte verwendet [...]» (EphW, § 9 A). 
melhor do que julga ou, se o pensar deve porventura valer na física como algo de mau, [...] ela é pior do que julga».

O método filosófico parte, por conseguinte, de um dado domínio empírico e factual, seja ele constituído pelas ciências positivas, pelas instituições e criações culturais, religiosas, históricas, e nelas encontra uma ordem imanente. Esta ordem, contudo, é estabelecida não por associações a ocorrer no sujeito cognoscitivo, ou teorético, atribuíveis à sua constituição subjectiva contingente, mas é construída dialecticamente, ou seja, por factores críticos e refutativos. A dialéctica é uma ordenação refutativa dos seus conteúdos. A sua racionalidade é, pois, inerentemente crítica e - num certo sentido - a posteriori. A dialéctica hegeliana não pretende derivar ou deduzir a priori leis empíricas ou, ainda menos, factos a partir da razão. A sua função é a de uma ordenação e reconstrução ideal, a partir de relações — tipicamente de oposição conceptual — que os dados de facto estabelecem entre si. Esta ordenação, seja ela de categorias significativas, de conteúdos históricofilosóficos, científicos, culturais, institucionais ou outros, permite reconstruí-los num sistema de relações argumentativa ou eristicamente regulado. Este é um plano ideal que se autonomiza perante o seu pressuposto empírico, e a ele retorna, encontrando a sua confirmação. Trata-se de um procedimento, na sua génese, circular, que se poderia comparar a uma reflexão de tipo hermenêutico, mas dela distinto pela reivindicação de uma autonomia de princípio do pensar, e da indispensabilidade do sujeito sob a forma do método. Esta autonomia funda-se inteiramente na sua capacidade crítica, argumentativa e refutativa. O plano ideal autonomizado selecciona e ordena um conjunto de factos ou conteúdos disponíveis, tendo esta selecção e ordenação o sentido não de construir sistemas segundo algum arbítrio, mas de fazer destacar a sua racionalidade intrínseca — ou seja, de neles reconhecer os produtos sedimentados da própria actividade crítica do sujeito.

(28) «...da $\beta$ in ihr viel mehr Gedanke ist, als sie zugibt und wei $\beta$, da $\beta$ sie besser ist, als sie meint, oder, wenn etwa gar das Denken in der Physik für etwas Schlimmes gelten sollte, da $\beta$ sie schlimmer ist, als sie meint” (EphW, II, p. 11). 
Neste sentido, "a filosofia deve à experiência o seu surgimento inicial». (29) Uma vez dela originada, porém, dispensa o pressuposto que lhe deu origem, ordena-se numa auto-referência, e não mais tem «a vantagem, que cabe às outras ciências, de poder pressupor os seus objectos [...] bem como o método". (30) A partir do ponto em que o sujeito passa a reconhecer-se como autónomo e auto-referente, a sua relação com a empiria é invertida e submetida a um processo de novo reconhecimento, como uma verificação na realidade. Assim, para além da tarefa de determinar os conceitos, "O curso filosófico deve designar [...] qual o fenómeno empírico que corresponde à determinação conceptual e dele mostrar que de facto lhe corresponde».(31) É requerida uma "dedução transcendental», em virtude da inevitável diferenciação entre o plano real e o plano conceptual em que a razão se mostra. A condição essencial desta "dedução" é a possibilidade de a razão se reconhecer no real. Se, de facto, ela encontrar o real já como o processo da sua efectivação, não segundo uma finalidade exterior, mas numa teleologia imanente, ela pode afirmar tanto a sua autonomia transcendental quanto a essencial liberdade do real. Nestas condições, nenhuma racionalidade que obedeça a uma teleologia exterior - como, e.g., a racionalidade técnica - pode efectivar o reconhecimento de si da razão na realidade.

A perda da identidade entre os dois planos assim estabelecida, entre o plano do pensamento autonomizado, e o da empiria original - não-identidade que Hegel designa de «auto-diferenciação" ou «especulação» — não é, consequentemente, integral, uma vez que no plano real, fáctico, está garantida, desde logo, a presença de uma racionalidade reconhecível pelo pensar. Este encontra-se, assim, sempre já parcialmente realizado, ou em

(29) «[D]ie Philosophie verdanke der Erfahrung [...] ihre erste Entstehung» (EphW, § 12 A).

(30) "Die philosophie entbehrt des Vorteils, der den anderen Wissenschaften zugute kommt, ihre Gegenstände [...] sowie die Methode [...] voraussetzen zu können» (EphW, § 1).

(31) «[I]n dem philosophischen Gang [es ist namhaft zu machen] welche derselben [sc. der Begriffsbestimmungen] entspricht, und von ihr aufzuzeigen ist, da $\beta$ sie jener in der Tat entspricht” (EphW, § 246 A). 
realização no real, (32) ou não se encontra de todo - nem no outro nem a si mesmo. Se não se encontrasse, porém, tão-pouco se poderia produzir alguma lógica crítica e reflexiva para o pensar, em abstracto, ou uma qualquer realização desse pensar, em concreto. Neste sentido, o desenvolvimento espiritual ou cultural concreto é condição necessária da filosofia, pelo que esta, sem perder a sua autonomia, é parte integrante da sua época. Por isso, a tomada de consciência da identidade autónoma do sujeito é garantia suficiente da - sempre limitada — racionalidade do real. A identidade da razão é, em consequência, sempre reflectida na realidade empírica, que ela não pode deduzir a partir de si, mas a que não submete, tão-pouco, a sua capacidade negativa, i.e., crítica.

O carácter «especulativo» do método reside, para Hegel, justamente neste estatuto de permanente autonomização entre diferentes esferas independentes de significação, sendo que a autonomização da esfera auto-reflexiva do pensar permite a filosofia e a fundamentação do conhecimento.

Escreve Hegel que o seu método é "tanto analítico [...] quanto sintético", (33) mas deveríamos classificá-lo, antes, como reflexivo ou especulativo. Em linguagem kantinana, à disjunção: ou a priori e analítico ou a posteriori e sintético, Hegel responde com o especulativo nem uma coisa nem outra, de um método que não se funda nem na dedução a priori a partir de hipóteses ou axiomas segundo regras, nem na observação empírica ou na aceitação fundamental dos conteúdos culturais e históricos enquanto tais, mas no reconhecimento.

A dificuldade de explanação geral do método dialéctico deriva da sua recusa de uma reflexão exterior, posto que, conforme referido, a determinação provém "do seu próprio objecto». (34) Uma apreciação assim programática e geral do método hegeliano enferma, então, da exterioridade que ele próprio recusa, e só pode ser validada na medida em que reflecte, ainda que de

(32) V. EphW, § 234 Z.

(33) «Der Fortgang [...] ist ebensowohl analytisch [...] als synthetisch» (Eph.W, § 391 A).

(34) LB, p. 291. 
modo autonomizado, a operação efectiva do pensar e que nela possa de novo encontrar, em concreto, a sua confirmação. Esta dificuldade, embora não afecte a legitimidade de uma reflexão acerca do método, remete principalmente para o trabalho da sua confirmação no exercício do pensar nas diferentes áreas das ciências filosóficas. (35)

(35) V. o nosso livro supracitado Ferrer, Lógica e Realidade em Hegel (Centro de Filosofia, Lisboa, 2006) ou o artigo "O Singular e o Vivente em Hegel» (a sair in Actas do Colóquio O Estatuto do Singular, Lisboa, 2007). 


\section{Série}

\section{Documentos}

Imprensa da Universidade de Coimbra

Coimbra University Press

2007

- U

C • 